\title{
Exploring summertime organic aerosol formation in the eastern United States using a regional-scale budget approach and ambient measurements
}

\author{
Benjamin N. Murphy ${ }^{1}$ and Spyros N. Pandis ${ }^{1,2}$ \\ Received 26 April 2010; revised 5 October 2010; accepted 6 October 2010; published 31 December 2010.
}

[1] We present a new method for estimating the overall organic aerosol (OA) formation rate at the regional scale using a chemical transport model (CTM), PMCAMx-2008, and an extensive set of measurements (Speciation Trends Network, Interagency Monitoring of Protected Visual Environments, Pittsburgh Air Quality Study, Southeastern Aerosol Research and Characterization) for the eastern United States. PMCAMx-2008 takes into account up-to-date OA formation theory including primary OA evaporation, updated secondary OA (SOA) yields from traditional volatile organic precursor gases and multigenerational oxidation chemistry (aging) of vapors from anthropogenic sources, which lowers the volatility of the OA distribution over time. An overall OA formation rate of $22 \pm 5 \mathrm{ktons} \mathrm{d}^{-1}$ is consistent with available measurements for this summer time period. We perform an extensive sensitivity analysis of uncertain OA model processes to demonstrate the relationship between the estimated total OA production rate and model performance. Perturbing, within reasonable limits, emissions of volatile precursors, SOA yields from isoprene oxidation, and the solubility of organic vapors produces model predictions for total OA that deviate little from the base case performance. The fractional error and fractional bias vary by less than $6 \%$ and $13 \%$, respectively. These cases also result in total OA formation rates within $5 \mathrm{ktons} \mathrm{d}^{-1}$ of the base case. Neglecting chemical aging of anthropogenic OA components results in OA levels significantly lower than the observations everywhere, while aging biogenic SOA with the same parameters used for the base case anthropogenic SOA aging results in overpredictions in both the South and Midwest United States. Aging biogenic and anthropogenic SOA together with a reduced aging reaction rate results in reasonable model performance and an OA formation

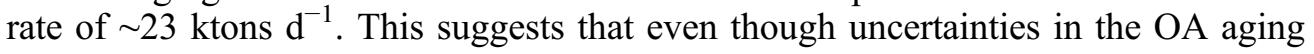
mechanism and other important parameters may lead to uncertainties in the contributions of specific OA formation pathways, the proposed approach may be used to infer upper and lower limits on the total OA mass formation rate.

Citation: Murphy, B. N., and S. N. Pandis (2010), Exploring summertime organic aerosol formation in the eastern United States using a regional-scale budget approach and ambient measurements, J. Geophys. Res., 115, D24216, doi:10.1029/2010JD014418.

\section{Introduction}

[2] Organic aerosol (OA) contributes significantly to the total submicron particulate mass [Zhang et al., 2007], thus influencing physicochemical properties of atmospheric particulate matter. OA remains poorly understood due to incomplete characterization of organic compounds present

\footnotetext{
${ }^{1}$ Department of Chemical Engineering, Carnegie Mellon University, Pittsburgh, Pennsylvania, USA.

${ }^{2}$ Institute of Chemical Engineering and High Temperature Chemical Processes (ICE-HT), Foundation for Research and Technology - Hellas (FORTH), Patra, Greece.

Copyright 2010 by the American Geophysical Union. 0148-0227/10/2010JD014418
}

in the atmosphere and complex chemical processing [Kanakidou et al., 2005; Goldstein and Galbally, 2007].

[3] There are several known pathways for atmospheric organic aerosol formation including direct emission and oxidation of gaseous precursors followed by condensation of the resulting products. Although these mechanisms have been identified in the laboratory, uncertainties exist in extrapolating these results to the atmosphere through CTMs [Kanakidou et al., 2005; Fuzzi et al., 2006]. Recent evaluations of such CTMs have shown that production by these pathways fails to explain the OA levels observed in the atmosphere [Morris et al., 2006; Donkelaar et al., 2007; Gaydos et al., 2007]. However, Murphy and Pandis [2009] found that PMCAMx-2008 reproduces relatively well the OA concentrations and highly oxygenated nature of the 
organic particles for the eastern United States during July 2001. That study reported fractional errors of $0.34-0.52$ and correlation coefficients of $0.50-0.62$ for comparisons to daily averaged measurements at sites throughout the United States and hourly measurements at Pittsburgh.

[4] OA absorptive partitioning theory is implemented in PMCAMx-2008 with the volatility basis set (VBS) framework introduced by Donahue et al. [2006]. Under this framework, the saturation concentrations of OA surrogate species are fixed, typically with a separation of 1 order of magnitude (e.g., Murphy and Pandis [2009] used nine surrogates to describe primary organic aerosol (POA) semivolatile absorptive portioning with saturation concentrations from 0.01 to $10^{6} \mu \mathrm{g} \mathrm{m}^{-3}$ ). In this way, the VBS model describes a nearly complete range of atmospherically relevant saturation concentrations and allows a straight-forward representation of the effect of multiple generation chemistry on volatility [Shrivastava et al., 2008]. During each time step, the rate of hydroxyl radical reaction with a condensable organic gas surrogate can be calculated, and assuming the reaction acts just to add functionality to the organic reactant, the product mass is moved to lower volatility surrogates. Although the parameters for OA formation and aging used in the VBS module are informed by smog chamber and field studies, there is still some uncertainty present. Research continues into constraining stoichiometric yields and the enthalpy of vaporization for the oxidation products of volatile organic precursors as a function of saturation concentration [Hallquist et al., 2009], but there can be significant uncertainties in these parameters, especially at exceedingly high and low loadings $\left(C_{\mathrm{OA}}>1000 \mu \mathrm{g} \mathrm{m}^{-3}\right.$ or $\left.C_{\mathrm{OA}}<1 \mu \mathrm{g} \mathrm{m}^{-3}\right)$ where existing data are sparse [Stanier et al., 2008]. For multiple generation chemistry, the $\mathrm{OH}$ reaction rate constant and the effective volatility reduction of the reaction products must be specified. As discussed later, the model's prediction for both the total OA concentration and composition are quite sensitive to this process. Recent studies have sought to constrain these parameters by comparing aging models to laboratory experiments [Grieshop et al., 2009] and ambient observations [Lane et al., 2008a; Dzepina et al., 2009; Murphy and Pandis, 2009; Pye and Seinfeld, 2010]. In addition to the eastern United States evaluation by Murphy and Pandis [2009], the VBS framework with multiple generation chemistry has improved predictions at the local scale in Mexico City during the MILAGRO campaign [Tsimpidi et al., 2010] and at the global scale in the Goddard Institute for Space Studies General Circulation Model II' [Farina et al., 2010]. Hodzic et al. [2010] revisited the MILAGRO campaign with an alternative organic gas aging mechanism following Grieshop et al. [2009] and found it to generally overpredict organic aerosol mass by $45 \%$ and $70 \%$ at the urban and suburban measurement sites.

[5] PMCAMx-2008 takes into account OA formation from the oxidation of traditional volatile precursors (anthropogenic and biogenic) to form secondary organic aerosol (SOA), as well as the semivolatile partitioning of POA. Multiplegeneration oxidation (aging) of condensable organic gases to lower volatility is also treated, following the work of Lane et al. [2008b] for SOA aging and Shrivastava et al. [2008] for POA. Finally, PMCAMx-2008 simulates emissions and oxidation of intermediate volatility organic compounds
(IVOCs) that are believed to be missing from current emission inventories used by CTMs [Grieshop et al., 2009]. Although semivolatile partitioning of POA compounds was important for improving model performance, the largest contribution to reducing OA underprediction came from aging traditional SOA vapors. Taking advantage of the ability of PMCAMx-2008 to reproduce the observed OA concentration field, we will estimate the magnitude of total OA formation and removal rates, even though the contribution from each specific source category may remain highly uncertain. The robustness of this method and the predicted total rates can be tested by combining a set of sensitivity tests (which will further demonstrate the variability of each source's contribution) with the available measurements.

[6] Global CTMs typically use a budget analysis to calculate the atmospheric burden, formation rate, and removal rate of a pollutant of interest [Chung and Seinfeld, 2002; Tsigaridis and Kanakidou, 2003; Henze et al., 2008]. These estimates are useful for comparing models using different chemical and transport schemes as well as for constraining the total pollutant source rate. Organic aerosol formation has been widely studied at the global scale with this analysis, and models using a bottom-up approach, in which SOA formation is estimated with yields determined from experimental smog chamber results, have found POA emission

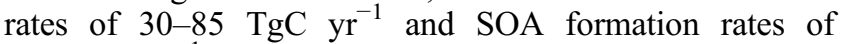
12-70 $\mathrm{Tg} \mathrm{yr}^{-1}$ [Chung and Seinfeld, 2002; Kanakidou et al., 2005; Heald et al., 2008; Henze et al., 2008]. However, the usefulness of OA production estimates from global simulations for regional scales is limited by low spatial and temporal resolution. Many of these models do not reproduce OA observations well, and so their corresponding budgets remain uncertain. Regional-scale models, on the other hand, can make direct comparisons to measurements in areas with high OA concentrations. Although the final budget estimates from a regional-scale model would be averaged over the entire domain and simulation period, the individual processes (emissions, wet deposition, chemistry, partitioning, etc.) would be calculated at the $36 \mathrm{~km}$ scale, introducing higher resolution for investigating urban/suburban environments and the influence of anthropogenic sources on OA. This application has not been pursued in the past due, in part, to biases introduced by the uncertain boundary conditions needed by these CTMs. We propose here a scheme to minimize this uncertainty by analyzing a smaller subset of the regional CTM domain thereby avoiding grid cells where the influence of the boundary conditions is high.

[7] In this work, we describe our treatment of organic aerosol in the three-dimensional CTM, PMCAMx-2008 for a summer period in the eastern United States followed by several test cases with varied model parameters to explore the uncertainty in the overall model performance introduced by the uncertainty in specific model processes. We further use ambient observations to assess the reasonableness of each case. After estimating the rate of total OA formation for each of these scenarios, we can again use ambient observations to pinpoint $\mathrm{OA}$ production rates that are not likely to occur in the atmosphere. Finally, we use our base case model to estimate (despite the corresponding uncertainties) a source-resolved budget for the production and 
Table 1. Updated Stoichiometric SOA Yields for Gas-Phase Precursors ${ }^{\mathrm{a}}$

\begin{tabular}{|c|c|c|c|c|c|c|c|c|}
\hline \multirow[b]{2}{*}{ VOC } & \multicolumn{4}{|c|}{ High- $\mathrm{NO}_{x}$ Parameterization } & \multicolumn{4}{|c|}{ Low-NO ${ }_{x}$ Parameterization } \\
\hline & 1 & 10 & 100 & 1000 & 1 & 10 & 100 & 1000 \\
\hline ALK4 & 0.0000 & 0.0375 & 0.0000 & 0.0000 & 0.0000 & 0.0750 & 0.0000 & 0.0000 \\
\hline ALK5 & 0.0000 & 0.1500 & 0.0000 & 0.0000 & 0.0000 & 0.3000 & 0.0000 & 0.0000 \\
\hline OLE1 & 0.0008 & 0.0045 & 0.0375 & 0.1500 & 0.0045 & 0.0090 & 0.0600 & 0.2250 \\
\hline OLE2 & 0.0030 & 0.0255 & 0.0825 & 0.2700 & 0.0225 & 0.0435 & 0.1290 & 0.3750 \\
\hline ARO1 & 0.0107 & 0.2571 & 0.4821 & 0.7500 & 0.0107 & 0.2571 & 0.7500 & 0.9643 \\
\hline $\mathrm{ARO} 2$ & 0.0015 & 0.1950 & 0.3000 & 0.4350 & 0.0750 & 0.3000 & 0.3750 & 0.5250 \\
\hline ISOP & 0.0003 & 0.0225 & 0.0150 & 0.0000 & 0.0090 & 0.0300 & 0.0150 & 0.0000 \\
\hline SESQ & 0.0750 & 0.1500 & 0.7500 & 0.9000 & 0.0750 & 0.1500 & 0.7500 & 0.9000 \\
\hline TERP & 0.0120 & 0.1215 & 0.2010 & 0.5070 & 0.1073 & 0.0918 & 0.3587 & 0.6075 \\
\hline
\end{tabular}

${ }^{\mathrm{a}} \mathrm{All}$ yields are based on an SOA density of $1.5 \mathrm{~g} \mathrm{~cm}^{-3}$.

removal of OA in the eastern United States for this summer simulation.

\section{PMCAMx-2008 Description}

[8] The CTM PMCAMx-2008 is configured to simulate a summer period (12-28 July 2001) over the eastern United States with $36 \mathrm{~km} \times 36 \mathrm{~km}$ horizontal resolution and 14 model layers corresponding to a $6 \mathrm{~km}$ column depth [Murphy and Pandis, 2009]. The model uses inorganic and organic compound emission rates from the 1999 and 2002 National Emissions Inventories, respectively [U.S. Environmental Protection Agency (USEPA), 2001, 2004]. Vehicular emissions are calculated by MOBILE6 [USEPA, 2002], and biogenic emissions are supplied by the Biogenic Emissions Inventory System (version 3.13) [Schwede et al., 2005]. MM5 simulates the meteorology for the simulation period [Grell et al., 1995].

[9] PMCAMx-2008 computes pollutant concentration changes due to emission, advection, turbulent dispersion, dry and wet deposition, and gas-phase chemistry and simulates inorganic and organic aerosol microphysics using 3 combined inorganic and organic aerosol models [Gaydos et al., 2007] and 10 size sections with diameters ranging from $40 \mathrm{~nm}$ to $40 \mu \mathrm{m}$. Model performance for inorganic $\mathrm{PM}_{2.5}$ species varies from average (fractional bias $\leq \pm 60 \%$ and fractional error $\leq 75 \%$ ) to excellent (fractional bias $\leq \pm 15 \%$ and fractional error $\leq 35 \%$ ) throughout all seasons in 2001 for this domain [Karydis et al., 2007] when compared to daily averaged ambient measurements from the Speciation Trends Network (STN) [USEPA, 2003] and Interagency for Monitoring of Protected Visual Environments (IMPROVE) [IMPROVE, 1995] and hourly measurements made during the Pittsburgh Air Quality Study (PAQS) [Wittig et al., 2004]. Organic carbon concentrations were measured at six sites during the PAQS campaign. However, Tang et al. [2004] found little spatial variation in observations among the locations, so model comparisons will be made against observations only at the main site (Schenley Park, Pittsburgh, PA). For the current study, we have augmented the data set by including comparisons to two urban sites from the Southeastern Aerosol Research and Characterization (SEARCH) network [Hansen et al., 2003]. We include hourly measurements from Birmingham, AL and Jefferson Street in Atlanta, GA. All surface observations are directly compared to the concentration of the first model layer ( $\sim 32 \mathrm{~m}$ deep).

[10] Organic aerosols (OA) are treated as in the work of Murphy and Pandis [2009] except for the following updates.
Hildebrandt et al. [2009] investigated SOA formation from toluene oxidation with an aerosol mass spectrometer (AMS), taking special care to control the temperature in the smog chamber and correct for organic vapors that may have been lost to the chamber walls during their experiment. The stoichiometric yields for SOA production from the ARO1 species (representative of toluene and other monoalkyl benzenes) in the SAPRC-99 gas-phase chemical mechanism have been updated with their results. These new yields, although lower for semivolatile surrogates under low- $\mathrm{NO}_{x}$ conditions, are substantially higher for intermediate volatility species and all species formed in areas with high $\mathrm{NO}_{x}$ (where much of the ARO1 species are released according to the emissions inventory). Thus, incorporation of the new yields will lead to higher anthropogenic SOA formation overall. Table 1 shows the yields used for the base case in this work. Aerosol mass from the oxidation products of intermediate volatility organic compounds, defined as organic compounds with a saturation concentration between 100 and $10^{6} \mu \mathrm{g} \mathrm{m}^{-3}$, is tracked explicitly as nontraditional SOA (NT-SOA) using eight surrogate species with saturation concentrations separated by 1 order of magnitude ranging from 0.1 to $10^{6} \mu \mathrm{g} \mathrm{m}^{-3}$ (at $298 \mathrm{~K}$ ). In Murphy and Pandis [2009], these compounds were lumped together with the oxidized POA. The model includes OA from five sources: anthropogenic secondary OA (aSOA), biogenic SOA (bSOA), fresh (unoxidized) primary OA (fPOA), oxidized POA (oPOA), and OA transported into the domain by advection and dispersion from the boundaries (tOA).

[11] Traditional SOA is modeled using five surrogate species with saturation concentrations from 0.1 to $1000 \mu \mathrm{g} \mathrm{m}^{-3}$, while the POA species are treated similarly to NT-SOA with eight volatility bins $\left(0.1-10^{6} \mu \mathrm{g} \mathrm{m}^{-3}\right)$. The tOA mass, believed to be representative of heavily aged OA, is assumed to be nonvolatile and nonreactive. For this work, the tOA concentration specified at the model boundaries is $0.8 \mu \mathrm{g} \mathrm{m}^{-3}$ for the first 10 model layers $(\sim 2 \mathrm{~km})$ and $0.3 \mu \mathrm{g} \mathrm{m}^{-3}$ for layers 11-14 ( 2-6 km). The boundary conditions for the surface and atmospheric boundary layer are informed by observations from IMPROVE network sites in rural areas of the United States indicative of background concentrations. The boundary conditions decrease for higher layers more likely to include the free troposphere. This feature is consistent with aircraft measurements and global simulations of OA vertical concentration profiles [Heald et al., 2006; Morgan et al., 2010]. Pollutants can be transported through the top of the domain as well, and this removal term will be included with 


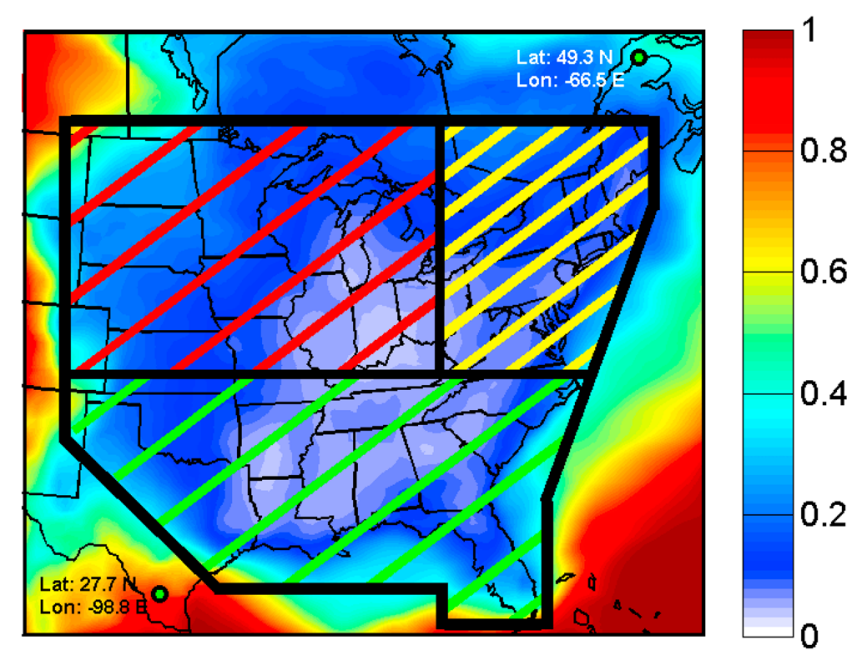

Figure 1. Horizontal view of the PMCAMx-2008 "subdomain," inside the black border, used for the budget analysis. The color axis indicates the surface layer fractional contribution of organic aerosol mass from the boundaries to the total mass for the simulation period. The red, yellow, and green hatched "subregions" inside the subdomain are used to segregate the midwest, northeast, and south geographical areas, respectively, when comparing to ambient measurements.

the overall transport out of the domain. The top boundary conditions (at $6 \mathrm{~km}$ ) are assumed $0 \mu \mathrm{g} \mathrm{m}^{-3}$ for all OA species.

[12] To reduce the influence of the uncertain OA boundary conditions, a smaller domain is constructed within the larger eastern United States domain (Figure 1) that captures cells with OA mass formed mainly from sources in the eastern United States while discarding cells where transported OA contributes more than approximately half of the total OA. The height of our mass balance domain is reduced from the $6 \mathrm{~km}$ used in PMCAMx to the first $2 \mathrm{~km}$, which includes all of the planetary boundary layer. The distribution of source types (biogenic, industrial, etc.) and the density of urban areas is not homogenous across the domain, so further analysis will be performed by dividing the OA budget domain into three geographical regions (northeast, midwest, and south) as shown in Figure 1. PMCAMx-2008 models OA by tracking the mass of organic matter (OM). However, the ambient measurements available are reported for organic carbon (OC). For this work an OM/OC ratio of 2 for oxidized species (aSOA, bSOA, oPOA, NT-SOA, and tOA) and 1.4 for the hydrocarbon-like fPOA mass are used as in the work of Murphy and Pandis [2009]. For the PAQS data set, Polidori et al. [2008] measured the OM/OC to be 1.8 so that value will be used to convert the total measured OC mass to OM. Uncertainty in the $\mathrm{OM} / \mathrm{OC}$ ratio can affect the error found in comparing model predictions to ambient data. However, a number of ambient studies indicate that the values used in this work are reasonable [Turpin and Lim, 2001; Aiken et al., 2008; $\mathrm{Ng}$ et al., 2009] and uncertainty in this ratio may be further reduced in the future when highresolution aerosol mass spectrometers are incorporated into more field missions.

[13] Our suite of sensitivity tests perturbs uncertain model parameters relevant to OA formation and removal (Table 2).
The base case (a) calculates the emission rate of IVOCs as 1.5 times the emission rate of fresh POA for every grid cell and time step [Robinson et al., 2007]. Sensitivity cases (b) and (c) perturb this ratio to 3 and 0 , respectively. The emission rates of sesquiterpenes have been estimated to be 9\%-30\% of monoterpene emissions [Helmig et al., 2007; Sakulyanontvittaya et al., 2008]. The base case for the present work assumes this value to be $30 \%$, in agreement with assumptions from Lane et al. [2008b]. Sensitivity test (d) employs a decreased value $(10 \%)$, which may be more representative of summertime behavior [Sakulyanontvittaya et al., 2008].

[14] Aerosol yields from oxidation of the volatile precursor, isoprene, have been widely studied but remain uncertain. Cases (e) and (f) vary the base case yields [Murphy and Pandis, 2009] to agree with the high-yield case from Lane et al. [2008b] and a modified version of the high $\mathrm{NO}_{x}$ yields reported by Carlton et al. [2009]. Water solubility of condensable gas-phase compounds, in the form of an effective Henry's law constant, is uncertain as well. This property determines the resistance for an organic vapor dry depositing to active leaf stomata and mesophyll. An increase in the effective Henry's law constant decreases the resistance to this dry deposition and enhances removal [Seinfeld and Pandis, 2006]. Prisle et al. [2010] measured the water solubility of organic vapors produced from the ozonolysis of $\alpha$-pinene, determining the volatility of these compounds to be relatively unaffected by the presence of water. The base case therefore assumes the effective Henry's law constant equals $2700 \mathrm{M}$ $\mathrm{atm}^{-1}$ at $300 \mathrm{~K}$. Case $(\mathrm{g})$ explores a high solubility case $\left(H^{\mathrm{eff}}=\right.$ $\left.10^{4} \mathrm{M} \mathrm{atm}{ }^{-1}\right)$, while case $(\mathrm{h})$ treats the compounds as very soluble $\left(H^{\text {eff }}=10^{5} \mathrm{M} \mathrm{atm}^{-1}\right)$ in closer agreement with some previous OA global and regional modeling studies [Chung and Seinfeld, 2002; Pun et al., 2003; Henze and Seinfeld, 2006]. Continued oxidation leading to a net reduction of volatility of the initial SOA products is explored in cases (i) (l) as shown in Table 2. PMCAMx-2008 assumes only homogenous gas-phase aging occurs with an $\mathrm{OH}$ oxidation rate constant of $10 \times 10^{-12} \mathrm{~cm}^{3}$ molec $^{-1} \mathrm{~s}^{-1}$. Although evidence for particle-phase reactions does exist [Hallquist et al., 2009], the rates of these processes are slower than those in the gas phase [Molina et al., 2004] and will be ignored in this study. The base case assumes only anthropogenic SOA and POA age to form lower volatility products. Case (i) neglects both anthropogenic and biogenic SOA aging, case (j) simulates aging of biogenic SOA with the same base case oxidation rate constant but neglects aging of anthropogenic SOA, in case (k) SOA from both sources ages with a reduced rate constant $\left(2.5 \times 10^{-12} \mathrm{~cm}^{3}\right.$ molec $\left.^{-1} \mathrm{~s}^{-1}\right)$, and in case (1) SOA from both sources ages with the base case rate constant. Comparing ground-level OA mass concentration predictions from each of these cases to ambient measurements and their corresponding total OA production rates provides useful insights about the range of rates that are compatible with the observations in all parts of the domain.

\section{Results and Discussion}

[15] The base case model performs well (Tables 3 and 4) when compared to daily (STN and IMPROVE) and hourly averaged (PAQS, SEARCH) organic aerosol (OA) concentrations measurements and, in this sense, presents one 
Table 2. Sensitivity Tests for PMCAMx-2008

\section{Sensitivity Test}

(a) Base Case

(b) IVOC Emissions $\times 2$

(c) No IVOC Emissions

(d) Low Sesquiterpene Emission Rates

(e) High Isoprene Yield

(f) Low Isoprene Yield

(g) High Solubility

(h) Very High Solubility

(i) No Traditional SOA Aging

(j) Biogenic SOA Aging

(k) Intermediate SOA Aging

(1) All Traditional SOA Aging

\section{Details}

Documented in the work of Murphy and Pandis [2009] with updated, higher SOA yields for toluene oxidation [Hildebrandt et al., 2009]

Ratio of IVOC mass to POA mass is set to 3

No IVOC emissions are added to the system

Emissions of sesquiterpene volatile organic gases are reduced to one-tenth that of terpenes

High-yield case from Lane et al. [2008b] is used for isoprene SOA oxidation Modified high- $\mathrm{NO}_{x}$ yield from Carlton et al. [2009] $\alpha\left(100 \mu \mathrm{g} \mathrm{m}^{-3}\right)=0.0203$

Effective Henry's coefficient for condensable gas-phase organic compounds equals $10^{4} \mathrm{M} \mathrm{atm}^{-1}$

Effective Henry's coefficient for condensable gas-phase organic compounds equals $10^{5} \mathrm{M} \mathrm{atm}^{-1}$

No aging of anthropogenic or biogenic SOA compounds Semivolatile POA species and nontraditional SOA compounds are still aged as in the base case

Biogenic SOA is aged the same as anthropogenic SOA from the base case Anthropogenic SOA is not aged. Semivolatile POA and nontraditional SOA are aged as usual

Anthropogenic and biogenic organic gases are aged with an $\mathrm{OH}$ reaction rate constant equal to $2.5 \times 10^{-12} \mathrm{~cm}^{3} \mathrm{molec}^{-1} \mathrm{~s}^{-1}$

Anthropogenic and biogenic SOA are aged with the same reaction rate Semivolatile POA and nontraditional SOA are aged as usual reasonable depiction of reality. The fractional error (FE) for all three networks is $<50 \%$, while the fractional bias (FB) magnitude is $\leq 26 \%$. The variation in FB among networks reveals a tendency for the model to overpredict OA in rural or forested areas (IMPROVE, SEARCH) and to underpredict in urban areas less dominated by biogenic sources (STN, PAQS). Correlation coefficients $(R)$ for the base case are comparable to other organic aerosol chemical transport models, with 0.60 and 0.51 for predictions at IMPROVE and STN sites, respectively. The root mean square error (RMSE) shows more variation in performance from IMPROVE to STN (RMSE $=1.20$ and 2.45, respectively). The base case model does quite well at predicting OA concentration in Pittsburgh with a resolution of $1 \mathrm{~h}$, with
$\mathrm{FE}=35 \%$ and $\mathrm{FB}=-7 \%$ when compared to the PAQS data set. Predictions for two urban areas from the SEARCH network, Birmingham and Atlanta, also show good agreement with observations (Figures 2 and 3, respectively). Although the performance is much closer to measurements in Birmingham $(\mathrm{FE}=0.45, \mathrm{FB}=-0.03)$, the model does capture the nearly flat profile of the Atlanta observations, despite consistently high bias $(\mathrm{FE}=0.54, \mathrm{FB}=0.39)$. The correlation coefficient and RMSE further support these conclusions. When the data are organized into geographical sub regions (Figure 1), the best performance is seen with sites in the south $(\mathrm{FE}=45 \%, \mathrm{FB}=-7 \%)$, with a little higher underprediction in the northeast ( $\mathrm{FE}=45 \%, \mathrm{FB}=-12 \%$ ). The Midwest comparisons show the least fractional bias
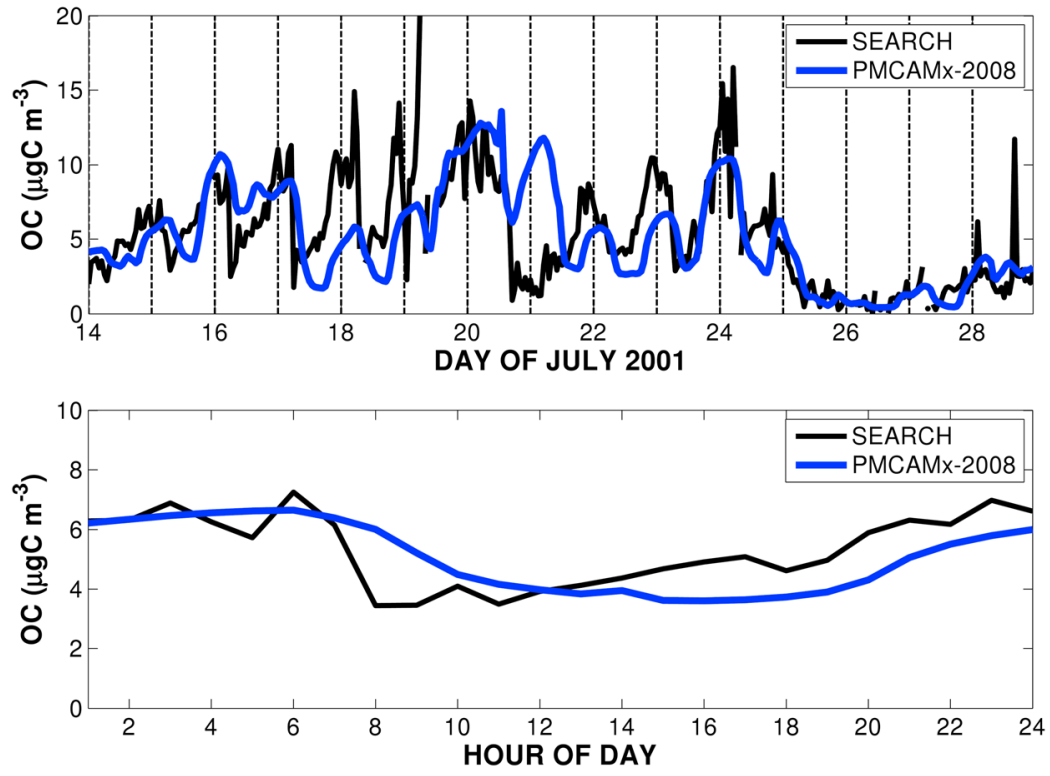

Figure 2. (top) Time series of PMCAMx-2008 predictions and observations made at the SEARCH site in Birmingham, AL for July 2001. (bottom) Diurnally averaged profile of the data in Figure 2 (top). 

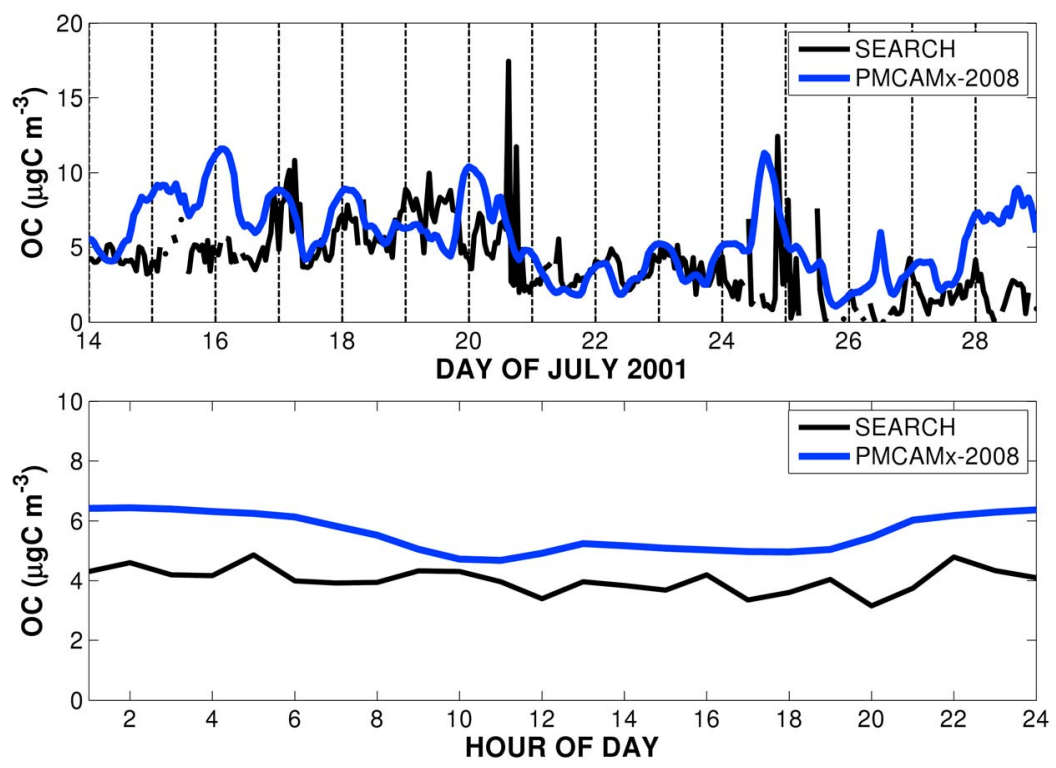

Figure 3. (top) Time series of PMCAMx-2008 predictions and observations made at the SEARCH site on Jefferson Street in Atlanta, GA for July 2001. (bottom) Diurnally averaged profile of the data in Figure 3 (top).

$(-1 \%)$, but this agreement is partly due to canceling errors between the IMPROVE and STN sites, as reflected by the fractional error $(48 \%)$, correlation coefficient $(0.39)$, and RMSE (3.48) for the Midwest, which indicate poorer performance than in the south or northeast.

[16] Tables 3 and 4 also present results from each of the sensitivity test cases. None of them perform better than the base case across all of the metrics calculated for this period. The high IVOC emissions case (b), results in a lower fractional bias magnitude than the base case when compared to STN sites, but overpredicts OA in the rural areas. The first seven test cases $(b-h)$ exhibit this phenomenon, where FE or FB improvements in one subregion or network are traded for significant decreases in agreement elsewhere. The similarity in performance for FE, FB correlation coefficient and RMSE among these first eight cases $(35 \% \leq \mathrm{FE} \leq 62 \%$ for all ambient comparisons) is partly the result of the predicted dominance of anthropogenic (including biomass burning) and long-range transported $\mathrm{OA}$ in the base case simulation. The contributions of these model species do not change drastically between these scenarios. The aging scheme sensitivity tests, on the other hand, show large deviation from the base case performance. Test (i), with no traditional SOA aging, results in about the same FE as the base case for IMPROVE sites (48\%), but it is clearly underpredicting OA in urban areas ( $\mathrm{FE}=77 \%, \mathrm{FB}=-67 \%)$. The agreement with the PAQS data set is especially bad, FE grows by more than a factor of 2 , and FB drops from $-7 \%$ to $-69 \%$. At the other extreme configuration of the aging module, test (l) ages aSOA and bSOA using the same base case rate constant for reaction with $\mathrm{OH}$ and, because so much more mass is being moved to lower volatility products, it overpredicts OA concentrations for all areas (FB $=57 \%$ and $14 \%$ for IMPROVE and STN comparisons, respectively). Test (j), where biogenic condensable vapors are aged instead of just anthropogenic vapors, performs as well as the base case in most urban sites, but strongly overpredicts OA in rural sites, even more than the high isoprene yield case (e). This case also overpredicts the Pittsburgh concentrations with an $\mathrm{FB}=$ $21 \%$. The intermediate SOA aging test (k) ages both aSOA and bSOA but uses a reduced $\mathrm{OH}$ reaction rate constant $\left(2.5 \times 10^{-12} \mathrm{~cm}^{3} \mathrm{molec}^{-1} \mathrm{~s}^{-1}\right)$. The scenario performs well, resulting in FE and FB estimates just 1\%-2\% higher than the base case in all metrics. Analysis from these four aging tests (i)-(l) emphasizes the significant effect that the OA aging parameters can have on predictions from regionalscale CTMs. It also suggests that there is little room for additional biogenic SOA sources in the rural areas of the eastern United States in at least the PMCAMx-2008 simulations, keeping in mind that there are significant uncertainties in the biogenic emissions inventory.

[17] The model performs well compared to contemporary organic aerosol modeling attempts of the same scale. Spak and Holloway [2009] modeled the Great Lakes with the community multiscale air quality (CMAQ) model for the year 2002, with significant underprediction in July for both the $\operatorname{STN}(\mathrm{FB}=-0.90, \mathrm{FE}=0.93)$ and $\operatorname{IMPROVE}(\mathrm{FB}=-0.68$, $\mathrm{FE}=0.72)$ networks. McKeen et al. [2007] used several models to forecast $\mathrm{PM}_{2.5}$ concentrations and composition for the 2004 International Consortium for Atmospheric Research on Transport and Transformation (ICARTT)/New England Air Quality Study (NEAQS). That study found the CMAQ model to perform best at predicting organic aerosol but still underpredict the median $24 \mathrm{~h}$ average by a factor of 2 in both urban and rural areas. Morris et al. [2006] found both CMAQ and the comprehensive air quality model with extensions (CAMx) to underpredict OA concentrations for 2002 when compared to the IMPROVE, STN, and SEARCH networks, although they did find strong performance improvement (comparable to that of this work) when they revised their SOA model with updated production pathways from monoterpenes, sesquiterpenes, and isoprene.

[18] The fractional error versus fractional bias segregated by geographical subregion from Table 3 is plotted for every 


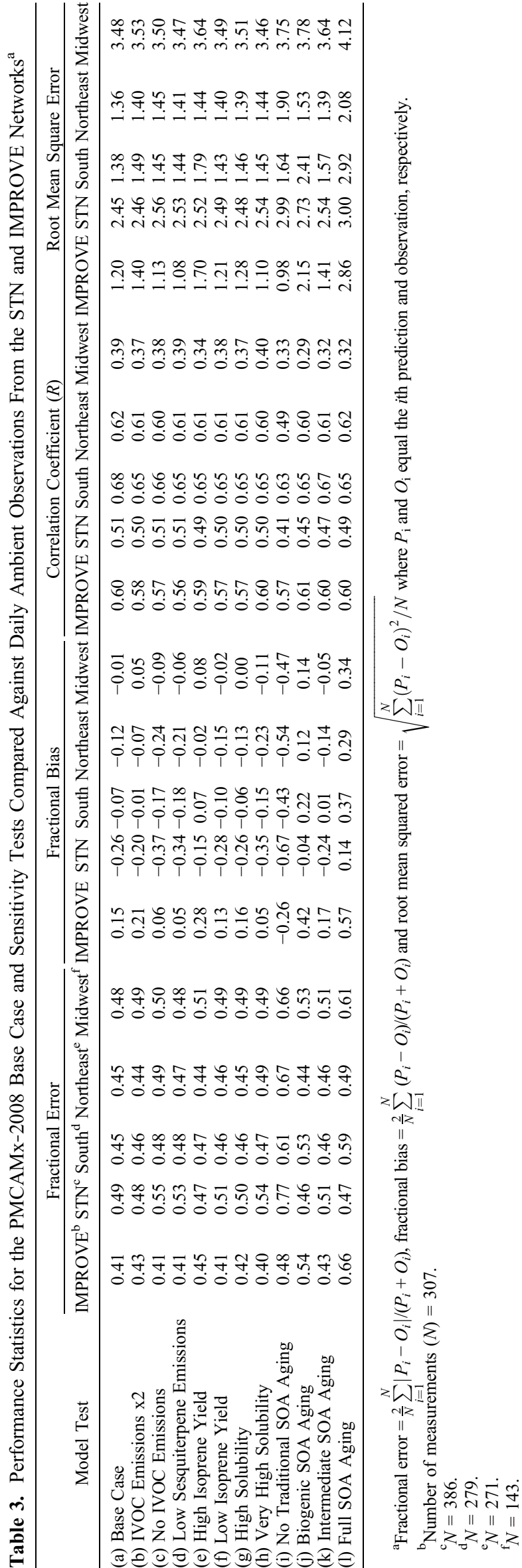

sensitivity test in Figure 4. Some scenarios, according to Figure 4, do poorly in all three regions and are thus obviously not realistic depictions of the atmosphere (cases (i) and (l)). Others however show mixed results (cases (c), (e), $(\mathrm{k})$, and (j)), performing well in one region but failing to reproduce observations in the other two. The base, high IVOC emissions, low sesquiterpene emissions, low isoprene yields, high-solubility, and very high solubility cases perform acceptably $(\mathrm{FE} \leq 50 \%$, $|\mathrm{FB}| \leq 30 \%)$ in all regions. This exercise is a useful approach for decoupling the effects of varying uncertain model parameters (e.g., biogenic precursor yields, IVOC emission rates, etc.). Moreover, the two-dimensional space in Figure 2 is well suited for visualizing how a model configuration change may improve or degrade performance. Specifically, a change from the base case (a) to the high IVOC emissions test (b) configuration results in improvement in both FB and FE for the northeast subregion. However, the opposite is true for the Midwest, which results in an $|\mathrm{FB}|$ increase equal to $4 \%$ and an FE increase equal to $1 \%$ when moving from the base case to case (b). The comparison for the south appears to suggest that the test (b) configuration performs better than the base case when looking at the significant improvement in FB $(-7 \%$ to $-1 \%)$, but the increase in FE (shift to the right in Figure 2) indicates the improvement is realized by offsetting STN and IMPROVE comparison errors. Taken together, the data for all of the acceptably performing sensitivity cases support conclusions drawn from the base case about PMCAMx-2008 performance in subregions across the domain. The northeast comparisons result in the strongest underpredictions, but also the least fractional error where only case (i) results in an $\mathrm{FE}>50 \%$. The model performs somewhat better in the south in terms of FB but also shows increased FE for most acceptable cases. FB estimates for the Midwest are quite good for most scenarios $(|\mathrm{FB}| \leq 10 \%)$, but the FE estimates reveal performance in this region may be more problematic than in the south or northeast.

[19] Each of these sensitivity tests can be used to calculate individual estimates of total OA formation rates averaged over the summertime simulation period. The OA formation rate for the base case is $21.6 \mathrm{ktons} \mathrm{d}^{-1}$ (Figure 5), with the majority coming from anthropogenic SOA formation pathways $\left(10.9\right.$ ktons $\left.\mathrm{d}^{-1}\right)$ followed by biogenic SOA

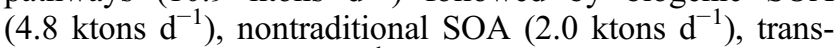
ported OA $\left(2.8 \mathrm{ktons} \mathrm{d}^{-1}\right)$, and primary organic aerosol (POA, fresh and oxidized) (1.1 ktons $\mathrm{d}^{-1}$ ). Interestingly, the aSOA production rate responds only slightly when the production rates of other species are perturbed. This feature occurs as a direct result of the aging mechanism. Because the model only ages gas-phase species, if the total OA concentration increases, the gas/particle equilibrium shifts toward the particle phase and less anthropogenic vapor is oxidized to lower volatility. Thus, there is a tradeoff, and the domain-wide response is less than what would be expected given traditional absorptive partitioning theory.

[20] Three of the last four tests, which vary the traditional SOA aging module, show formation rates that deviate significantly from this estimate. Case (i), which does not age traditional SOA, results in a substantially decreased formation rate $\left(\sim 9\right.$ ktons $\left.\mathrm{d}^{-1}\right)$, while case (j) (aging biogenic SOA), increases the formation rate to $33 \mathrm{ktons}^{-1}$, and case (l) (aging both anthropogenic and biogenic SOA) increases 
Table 4. Performance Statistics for the PMCAMx-2008 Base Case and Sensitivity Tests Compared Against Hourly Ambient Observation From the PAQS and SEARCH Networks

\begin{tabular}{|c|c|c|c|c|c|c|c|c|c|c|c|c|}
\hline \multirow[b]{2}{*}{ Model Test } & \multicolumn{3}{|c|}{ Fractional Error } & \multicolumn{3}{|c|}{ Fractional Bias } & \multicolumn{3}{|c|}{$\begin{array}{c}\text { Correlation } \\
\text { Coefficient }(R) \\
\end{array}$} & \multicolumn{3}{|c|}{$\underline{\text { Root Mean Square Error }}$} \\
\hline & $\mathrm{PAQS}^{\mathrm{a}}$ & $\mathrm{JST}^{\mathrm{b}}$ & $\mathrm{BHM}^{\mathrm{c}}$ & PAQS & JST & BHM & PAQS & JST & BHM & PAQS & JST & BHM \\
\hline (a) Base Case & 0.35 & 0.54 & 0.45 & -0.07 & 0.39 & -0.03 & 0.45 & 0.36 & 0.61 & 2.55 & 3.18 & 3.02 \\
\hline (b) IVOC Emissions x2 & 0.37 & 0.55 & 0.45 & 0.00 & 0.42 & 0.00 & 0.40 & 0.34 & 0.61 & 2.94 & 3.42 & 3.17 \\
\hline (c) No IVOC Emissions & 0.40 & 0.52 & 0.48 & -0.20 & 0.30 & -0.11 & 0.40 & 0.31 & 0.60 & 2.77 & 3.00 & 3.14 \\
\hline (d) Low Sesquiterpene Emissions & 0.38 & 0.47 & 0.50 & -0.14 & 0.18 & -0.26 & 0.40 & 0.36 & 0.61 & 2.72 & 2.48 & 3.14 \\
\hline (e) High Isoprene Yield & 0.36 & 0.62 & 0.49 & 0.05 & 0.54 & 0.21 & 0.38 & 0.29 & 0.57 & 3.31 & 4.40 & 4.43 \\
\hline (f) Low Isoprene Yield & 0.37 & 0.52 & 0.46 & -0.09 & 0.34 & -0.10 & 0.40 & 0.33 & 0.61 & 2.76 & 3.06 & 3.06 \\
\hline (g) High Solubility & 0.37 & 0.53 & 0.46 & -0.07 & 0.38 & -0.04 & 0.40 & 0.33 & 0.60 & 2.80 & 3.26 & 3.15 \\
\hline (h) Very High Solubility & 0.39 & 0.48 & 0.47 & -0.19 & 0.23 & -0.18 & 0.44 & 0.40 & 0.68 & 2.71 & 2.59 & 2.83 \\
\hline (i) No Traditional SOA Aging & 0.73 & 0.61 & 0.63 & -0.69 & 0.00 & -0.37 & 0.21 & 0.21 & 0.54 & 4.04 & 2.86 & 3.57 \\
\hline (j) Biogenic SOA Aging & 0.38 & 0.78 & 0.51 & 0.21 & 0.76 & 0.41 & 0.44 & 0.34 & 0.60 & 3.58 & 6.05 & 4.99 \\
\hline (k) Intermediate SOA Aging & 0.36 & 0.57 & 0.45 & -0.08 & 0.48 & 0.07 & 0.46 & 0.38 & 0.60 & 2.72 & 3.70 & 3.32 \\
\hline (1) Full SOA Aging & 0.51 & 0.88 & 0.58 & 0.45 & 0.87 & 0.53 & 0.45 & 0.37 & 0.62 & 5.54 & 7.14 & 5.70 \\
\hline
\end{tabular}

${ }^{\mathrm{a}}$ Number of measurements $(N)=307$. Data from this comparison are for organic matter $\left(\mu \mathrm{g} \mathrm{m}^{-3}\right)$.

${ }^{\mathrm{b}}$ Jefferson Street, Atlanta, GA; $N=328$. Data from this comparison are for organic carbon $\left(\mu \mathrm{gC} \mathrm{m}^{-3}\right)$.

${ }^{\mathrm{c}}$ Birmingham, $\mathrm{AL} ; N=348$. Data from this comparison are for organic carbon $\left(\mu \mathrm{gC} \mathrm{m}^{-3}\right)$.

the value to $43 \mathrm{ktons}^{-1}$. Cases (i) and (1) produce too little and too much OA compared to ambient observations (Table 3 and Figure 4) bounding in this way the overall OA production rate. Case (j) leads to unacceptable overprediction in the rural sites and the south in particular because many of the biogenic SOA precursors, based on the results of laboratory experiments, produce an abundance of intermediate volatility vapors $\left(100 \mu \mathrm{g} \mathrm{m}^{-3} \leq C^{*}<10,000 \mu \mathrm{g} \mathrm{m}^{-3}\right)$ that overwhelm OA concentrations if they are allowed to age with this full reaction rate constant and form products of lower volatility. The parameters for case $(\mathrm{k})$, the intermediate SOA aging case, lead to a similar rate of total OA formation $\left(23 \mathrm{ktons} \mathrm{d}^{-1}\right)$ as the base case, but the dominance of biogenic and anthropogenic SOA has reversed, with respective formation rates of

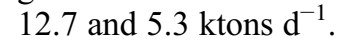

[21] Meanwhile, for the first seven sensitivity tests $(b-h)$, the total rate of formation varies by $\leq 5 \mathrm{ktons}^{-1}$. Cases (b) and (e) enhance the total formation rate by increasing uncertain precursor (IVOC) emissions and first-generation oxidation yields of condensable vapor products, respectively. On the other hand, cases (c), (d), and (f)-(h) suppress OA formation by decreasing precursor emissions (c, d), first-generation oxidation yields (f), and increasing deposition of condensable vapors by increasing water solubility (g, h). A regional-scale total OA formation rate of $22 \pm$ 5 ktons $\mathrm{d}^{-1}$ appears to be a necessary condition for acceptable model accuracy in the eastern United States during July 2001 based on our suite of sensitivity tests.

[22] The OA mass balance for the base case is illustrated in Figure 6 , with the formation rates displayed in three broad processes, transport in, emissions, and aerosol processes, which is net condensation to the particle phase. PMCAMx2008 predicts that direct primary OA emissions contribute the least organic particle mass to the atmosphere $\left(0.2 \mathrm{ktons}^{-1}\right)$.

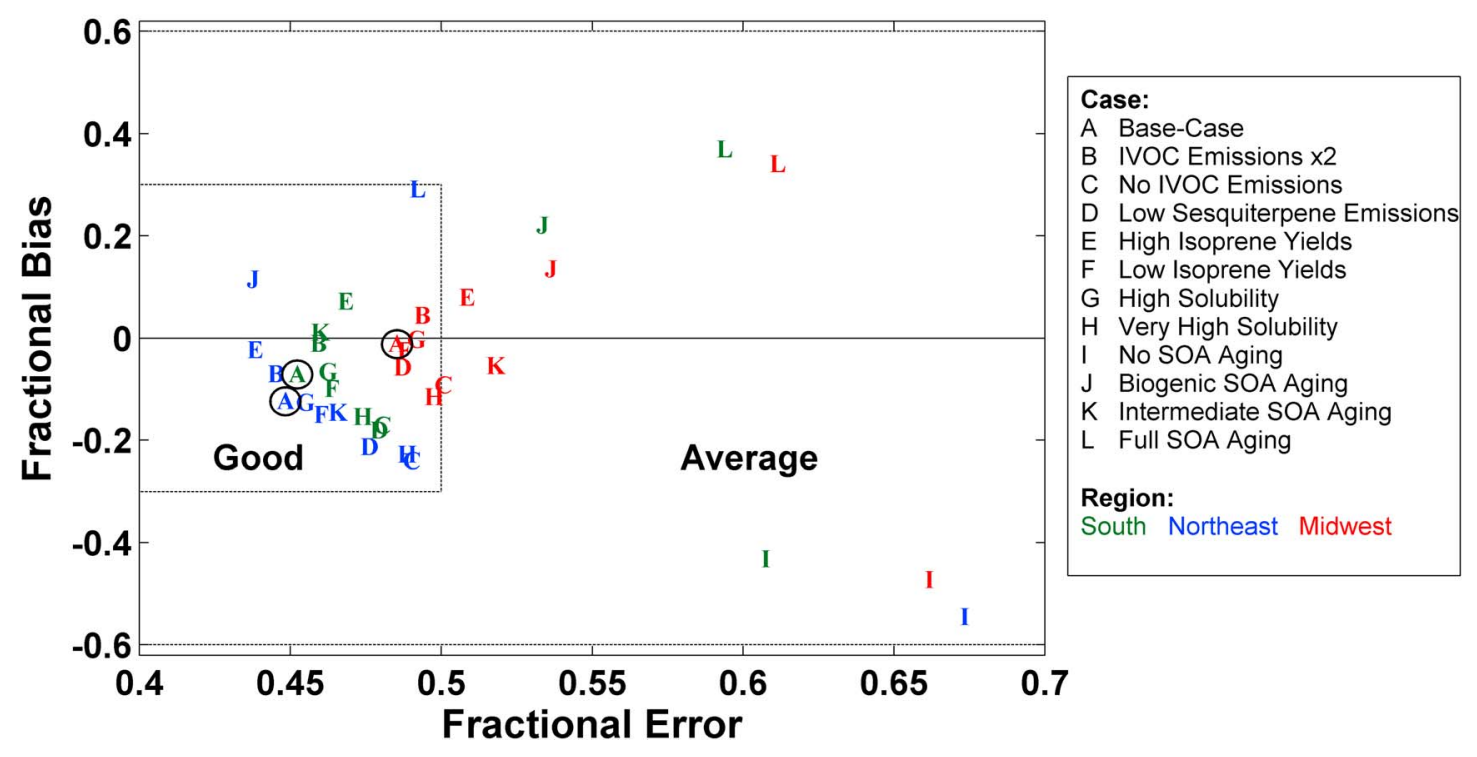

Figure 4. Fractional error is shown versus fractional bias for each scenario separated by domain region (illustrated in Figure 1). Also shown are the criteria for determining model performance as suggested by Morris et al. [2005]. 


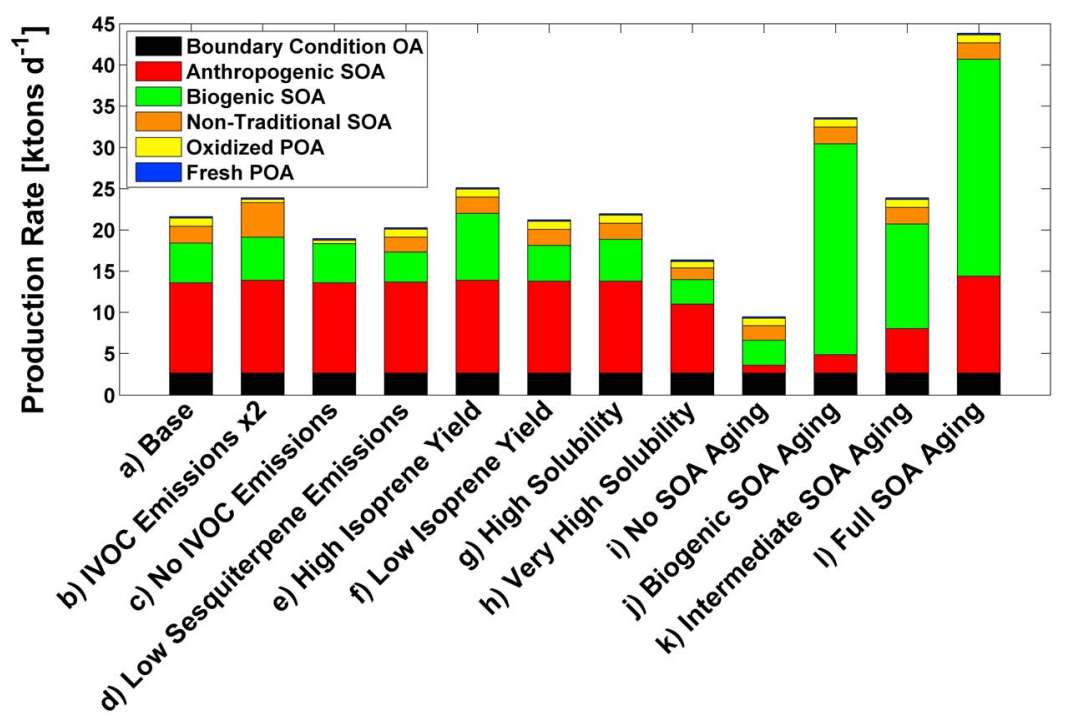

Figure 5. Organic aerosol mass production rate predicted by the PMCAMx-2008 base case and sensitivity tests. Calculations do not include the first two simulation days (model spin-up).

Evaporation of semivolatile POA $\left(C^{*} \geq 10 \mu \mathrm{g} \mathrm{m}^{-3}\right.$ partitions mostly to the vapor phase) plays a role in this ranking, and production of any POA from emissions that evaporates, oxidizes, and condenses back to the particle phase is accounted for in the aerosol processing category. The total mass emission rate of fresh POA (gas + particle) is 1.2 ktons $\mathrm{d}^{-1}$ in the inventory used so PMCAMx-2008 predicts the SOA formation pathway dominates the total formation rate in this summertime scenario even when POA is treated as nonvolatile. However, if POA were treated as nonvolatile, its concentrations in cities would be higher. The base case scheme results in a domain OA atmospheric burden of 25.7 ktons for this period, with $47 \%$ from anthropogenic SOA, 20\% from biogenic SOA, $8 \%$ from nontraditional SOA, $1 \%$ from fresh $\mathrm{POA}, 4 \%$ from oxidized POA, and $20 \%$ from OA transported from outside the domain. Because we perform this analysis on an interior domain, pollutants may be transported out of the domain and then back in. The magnitude of this process is estimated as the sum of all nontransport OA advected into the domain and shown in Figure 6 to be minimal (1.1 ktons d $\left.{ }^{-1}\right)$.

[23] Removal by wet deposition accounts for the most particle loss during this period $\left(\sim 13\right.$ ktons $\left.\mathrm{d}^{-1}\right)$, and transport out of the domain removes significant mass as well $\left(7.8 \mathrm{ktons}^{-1}\right)$. Dry deposition is predicted to be a minor removal pathway $\left(\sim 0.6 \mathrm{ktons} \mathrm{d}^{-1}\right)$, because particles must overcome resistance from diffusive transport across the quasi-laminar sublayer. The transport resistances, in this model implementation, are most unfavorable for deposition of accumulation mode particles, where most of the organic aerosol compounds reside [ENVIRON, 2006; Seinfeld and Pandis, 2006]. Recent studies have indicated, however, that this minimum in deposition velocity may be overstated by traditional dry deposition models [Pryor et al., 2008]. The overall removal rate sensitivity to wet scavenging below clouds was tested by increasing and decreasing the scavenging efficiency of particles by a factor of 2. Even for the enhanced removal rate case, in-cloud scavenging of OA dominated and the overall lifetime of particles due to wet removal did not change significantly. The peak for this in-cloud scavenging occurred at a height in the model consistent with about 1-1.4 km (870-854 mbar). The subdomain chosen includes the lower free troposphere and much of the domain-wide scavenging for this period. When the effective Henry's law coefficient is increased to $10^{5} \mathrm{M} \mathrm{atm}^{-1}$, a modest decrease is observed in the $\mathrm{OA}$ concentration at higher altitudes $(\sim 25 \%)$ due to enhanced water solubility and deposition. This is consistent with the results of Henze and Seinfeld [2006]. However, this test did not reveal the larger differences reported in that study, presumably because their global model used layers reaching to higher altitudes. The timing and spatial variation of modeled rain

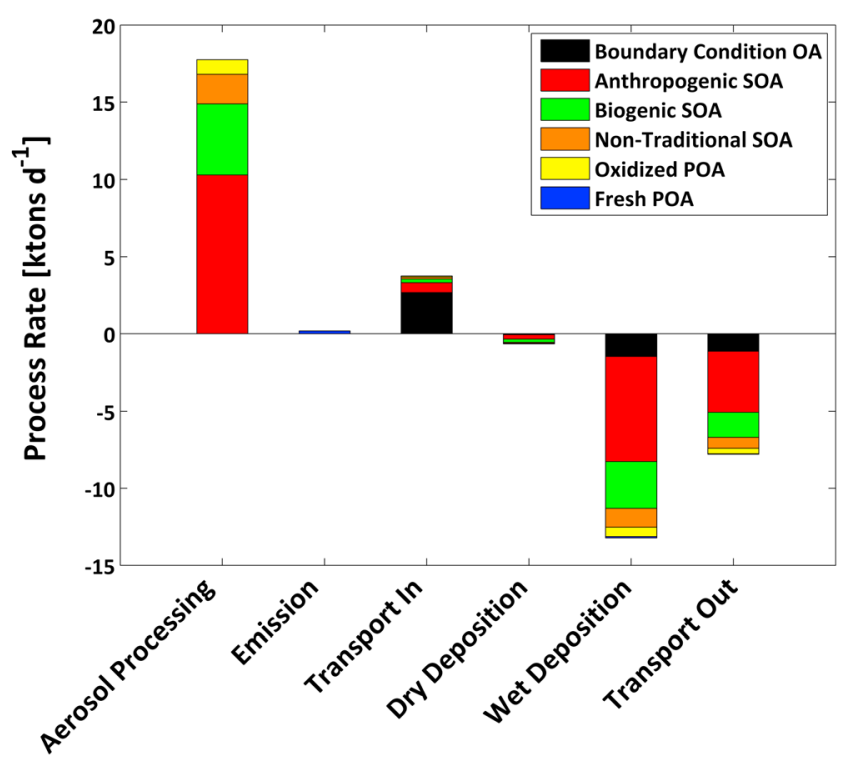

Figure 6. Organic aerosol mass balance for the base case PMCAMx-2008 simulation for 14-28 July 2001. Calculations do not include the first two simulation days (model spin-up). 
Table 5. Comparison Between Simulated Rainfall Data and Estimates From the North American Regional Reanalysis (NARR) Project

\begin{tabular}{|c|c|c|}
\hline Rainfall Inventory & $\begin{array}{l}\text { Simulated } \\
\text { (MM5) }\end{array}$ & $\begin{array}{l}\text { Observed } \\
\text { (NARR) }\end{array}$ \\
\hline Number of Events ${ }^{\mathrm{a}}$ & 431,621 & 254,063 \\
\hline Average Intensity $\left(\mathrm{mm} \mathrm{h}^{-1}\right)$ & 1.84 & 1.18 \\
\hline Percent of Events Collocated & $16 \%$ & $27 \%$ \\
\hline $\begin{array}{l}\text { Average Intensity During Collocated } \\
\text { Events }\left(\mathrm{mm} \mathrm{h}^{-1}\right)\end{array}$ & 2.15 & 1.19 \\
\hline $\begin{array}{l}\text { Average Intensity During } \\
\text { Noncollocated Events }\left(\mathrm{mm} \mathrm{h}^{-1}\right)\end{array}$ & 1.78 & 1.18 \\
\hline
\end{tabular}

${ }^{\mathrm{a}} \mathrm{An}$ event requires a rainfall rate greater than $0.45 \mathrm{~mm} \mathrm{~h}^{-1}$.

events is also an important source of uncertainty in CTM performance.

[24] An attempt to improve PMCAMx-2008 predictions was made by revising the precipitation fields with observed rainfall compiled by the National Centers for Environmental Prediction (NCEP) North American Regional Reanalysis (NARR) project [Mesinger et al., 2006]. Rainfall rate (mm $\mathrm{h}^{-1}$ ) observation data were obtained in the form of surface estimates (at $3 \mathrm{~h}$ resolution) and was distributed uniformly throughout the lowest $2 \mathrm{~km}$ of the model domain, which is consistent with the height of low-level precipitating clouds at midlatitudes [Seinfeld and Pandis, 1998]. The corrected data was then used in PMCAMx-2008 to calculate both inand below-cloud scavenging coefficients for all pollutant species. If only the locations and times with rainfall greater than $0.45 \mathrm{~mm} \mathrm{~h}^{-1}$ (PMCAMx-2008 minimum for calculating wet scavenging) are taken into account, significant differences are seen between the MM5 rainfall predictions and the NARR observations (Table 5). Overall, the MM5 simulation data are biased toward a greater number of rain events and slightly larger intensity on average than the NARR observations. Moreover, $16 \%$ and $27 \%$ of the events in the MM5 and NARR inventories, respectively, overlap in space and time (keeping in mind that this metric only accounts for events taking place in exactly the same cell during the same hour). Although these apparent differences exist, when the base case scenario for PMCAMx-2008 is run with NARR rainfall estimates, no significant improvement in OA prediction was seen. Another significant source of uncertainty for the wet removal term may arise from the coarse vertical resolution of PMCAMx-2008 above $2 \mathrm{~km}$. The model predicts a vertical trend in OA concentration that may be approximated with a scale height of about $1.8 \mathrm{~km}$. However, it is possible that the large model grid cells at higher altitudes overestimate wet scavenging in the lower free troposphere, leading to a larger significance for higher altitude wet removal processes. PMCAMx-2008 would need to be expanded to include higher altitudes aloft with better resolution in order to quantify this uncertainty.

[25] Using the total OA formation rate estimate, we can estimate the effect of adding proposed $\mathrm{OA}$ formation mechanisms to PMCAMx-2008. Fu et al. [2009] modeled OA formation from glyoxal and methylglyoxal in the aqueous phase using a global three-dimensional chemistry model (GEOS-Chem) for July to August 2004. Their model predicts that 130 ktons of organic carbon (OC) are produced from these compounds throughout the eastern United States during the entire simulation period. Using an organic matter to organic carbon ratio equal to 3, which Perri et al. [2009] determined for the particulate products of aqueous oxidation of glycolaldehyde, the production rate can be converted to roughly 6.4 ktons $\mathrm{d}^{-1}$ of $\mathrm{OA}$. Adding this formation mechanism to the base case model with no other changes will significantly affect the model's accuracy, especially since most of the particulate mass from the Fu et al. [2009] study was formed from biogenic precursors and our base case model already slightly overpredicts heavily forested areas. This mechanism may be an important pathway for OA formation in the atmosphere, but if it is to be included (as previous models have treated it) and accurate predictions of surface concentrations are desired, then the magnitude of other OA formation pathways must be decreased first by $5-10$ ktons $\mathrm{d}^{-1}$. This will require reductions primarily in the aSOA formation and potentially the existing biogenic SOA source.

\section{Conclusions}

[26] A method of constructing a budget for the regionalscale formation, transport, and deposition of organic aerosol (OA) and supporting those budget estimates with ambient measurements has been presented. PMCAMx-2008, which predicts OA surface concentrations well throughout the eastern United States during July 2001, also predicts an OA mass production rate of $21.6 \mathrm{ktons}^{-1}$ for this simulation period. Extrapolating this total OA production rate or the relative contribution of individual pathways to other seasons should be done with caution since factors like temperature, human activity, and photochemical activity will have significant effects on the importance of specific emission sources and the efficiency with which they lead to OA formation. The sensitivity tests chosen for this work explore a variety of model configurations, resulting in substantial variability for the contributions from specific OA formation pathways and a significant model performance range. Despite this variability, the reasonably performing tests predict total formation rates within approximately $5 \mathrm{ktons}^{-1}$ of the base case.

[27] The aging mechanism used for this work has many uncertain parameters, and its precise formulation has a large impact on the predicted importance of each OA surrogate species. The intermediate SOA aging case (k), where anthropogenic and biogenic SOA are aged with a reduced reaction rate constant, showed a similar total OA production rate to the base case $\left(\sim 23\right.$ ktons $\left.\mathrm{d}^{-1}\right)$, and somewhat reasonable model performance. This case also predicts OA formation will be dominated by the oxidation of biogenic SOA precursors rather than anthropogenic. The extreme configurations for the traditional SOA aging mechanism predict large differences in formation rates from the base case model $\left(<10\right.$ and $>30$ ktons $\left.\mathrm{d}^{-1}\right)$ but also have poor performance when compared to ambient measurements. These discrepancies suggests that at least some aging of mass from traditional SOA precursors is necessary to achieve reasonable model accuracy, but that aging all traditional SOA using the parameters from Murphy and Pandis [2009] can lead to unrealistically enhanced formation rates and poor model performance for this summertime simulation period. 
[28] One of the major issues discouraging analyses like this one in the past is the influence of boundary conditions; this work's method of focusing on a subdomain within the full one reduces the contribution of OA mass transported from outside the boundaries. Another major challenge for this work is the uncertainty in the simulated meteorological fields, which in some cases could dominate the uncertainty due to the OA formation mechanisms, especially if model evaluation is limited to comparing total organic aerosol concentrations. Future work should focus on exploiting other OA properties to evaluate model predictions (e.g., volatility, oxidation state, etc.). Although the organic aerosol module used for this model includes up-to-date SOA yields from traditional precursors, the relatively newly identified semivolatile partitioning of POA, and the oxidative aging of condensable organic gases, it does not include some other proposed mechanisms such as aqueous-phase processing of volatile precursors and heterogeneous oxidation of particle-phase compounds. Adding these new formation pathways to the current OA module would most likely cause this regional CTM to overpredict surface concentrations. This regional budget analysis approach may prove useful for estimating total $\mathrm{OA}$ formation rates for models using grid resolutions of tens of kilometers or finer and help inform the ongoing discussion of how to close the gap between model predictions and ambient measurements.

[29] Acknowledgments. This research was supported by the EPRI and the EPA STAR program through the National Center for Environmental Research (NCER). This paper has not been subject to EPA's required peer and policy review and therefore does not necessarily reflect the views of the agency. No official endorsement should be inferred.

\section{References}

Aiken, A. C., et al. (2008), O/C and OM/OC ratios of primary, secondary, and ambient organic aerosols with high-resolution time-of-flight aerosol mass spectrometry, Environ. Sci. Technol., 42, 4478-4485, doi:10.1021/ es 703009 q.

Carlton, A. G., et al. (2009), A review of secondary organic aerosol (SOA) formation from isoprene, Atmos. Chem. Phys., 9, 4987-5005.

Chung, S. H., and J. H. Seinfeld (2002), Global distribution and climate forcing of carbonaceous aerosols, J. Geophys. Res., 107(D19), 4407, doi:10.1029/2001JD001397.

Donahue, N. M., et al. (2006), Coupled partitioning, dilution, and chemica aging of semivolatile organics, Environ. Sci. Technol., 40, 2635-2643.

Donkelaar, A. V., et al. (2007), Model evidence for a significant source of secondary organic aerosol from isoprene, Atmos. Environ., 41, 1267-1274, doi:10.1016/j.atmosenv.2006.09.051.

Dzepina, K., et al. (2009), Evaluation of recently proposed secondary organic aerosol models for a case study in Mexico City, Atmos. Chem. Phys., 9, 5681-5709.

ENVIRON (2006), CAMx User's Guide, ver. 4.40, ENVIRON Intl. Corp., Novato, Calif.

Farina, S. C., et al. (2010), Modeling global secondary organic aerosol formation and processing with the volatility basis set: Implications for anthropogenic secondary organic aerosol, J. Geophys. Res., 115, D09202, doi:10.1029/2009JD013046.

Fu, T.-M., et al. (2009), Aqueous-phase reactive uptake of dicarbonyls as a source of organic aerosol over eastern north america, Atmos. Environ., 43, 1814-1822, doi:10.1016/j.atmosenv.2008.12.029.

Fuzzi, S., et al. (2006), Critical assessment of the current state of scientific knowledge, terminology, and research needs concerning the role of organic aerosols in the atmosphere, climate, and global change, Atmos. Chem. Phys., 6, 2017-2038.

Gaydos, T. M., et al. (2007), Development and application of a threedimensional aerosol chemical transport model, PMCAMx, Atmos. Environ., 41, 2594-2611, doi:10.1016/j.atmosenv.2006.11.034.
Goldstein, A. H., and I. E. Galbally (2007), Known and unexplored organic constituents in the Earth's atmosphere, Environ. Sci. Technol., 41, 1514-1521, doi:10.1021/es072476p.

Grell, G. A., et al. (1995), A Description of the Fifth-Generation Penn State/NCAR Mesoscale Model (MM5), Boulder, Colo. (Available at http://www.mmm.ucar.edu/mm5/documents/mm5-desc-doc.html)

Grieshop, A. P., et al. (2009), Laboratory investigation of photochemical oxidation of organic aerosol from wood fires: 1. Measurement and simulation of organic aerosol evolution, Atmos. Chem. Phys., 9, 1263-1277.

Hallquist, M., et al. (2009), The formation, properties and impact of secondary organic aerosol: Current and emerging issues, Atmos. Chem. Phys., 9, 5155-5236.

Hansen, D. A., et al. (2003), The southeastern aerosol research and characterization study: Part 1. Overview, J. Air Waste Manage., 53, 1460-1471.

Heald, C. L., et al. (2006), Concentrations and sources of organic carbon aerosold in the free troposphere over North America, J. Geophys. Res., 111, D23S47, doi:10.1029/2006JD007705.

Heald, C. L., et al. (2008), Predicted change in global secondary organic aerosol concentrations in response to future climate, emissions, and land use change, J. Geophys. Res., 113, D05211, doi:10.1029/2007JD009092.

Helmig, D., et al. (2007), Sesquiterpene emissions from pine trees identifications, emission rates and flux estimates for the contiguous united states, Environ. Sci. Technol., 41, 1545-1553, doi:10.1021/es0618907.

Henze, D. K., and J. H. Seinfeld (2006), Global secondary organic aerosol from isoprene oxidation, Geophys. Res. Lett., 33, L09812, doi:10.1029/ 2006 GL025976.

Henze, D. K., et al. (2008), Global modeling of secondary organic aerosol formation from aromatic hydrocarbons: High- versus low-yield pathways, Atmos. Chem. Phys., 8, 2405-2421.

Hildebrandt, L., et al. (2009), High formation of secondary organic aerosol from the photo-oxidation of toluene, Atmos. Chem. Phys., 9, 2973-2986.

Hodzic, A., et al. (2010), Modeling organic aerosols in a megacity: Potential contribution of semivolatile and intermediate volatility primary organic compounds to secondary organic aerosol formation, Atmos. Chem. Phys, 10, 5491-5514, doi:10.5194/acp-10-5491-2010.

IMPROVE (1995), Improve Data Guide, Univ. of California-Davis. (Available at http://vista.cira.colostate.edu/improve/Publications/OtherDocs/ IMPROVEDataGuide/IMPROVEDataGuide.pdf)

Kanakidou, M., et al. (2005), Organic aerosol and global climate modeling: A review, Atmos. Chem. Phys., 5, 1053-1123.

Karydis, V. A., et al. (2007), Evaluation of a three-dimensional chemical transport model (PMCAMx) in the eastern united states for all four seasons, J. Geophys. Res., 112, D14211, doi:10.1029/2006JD007890.

Lane, T. E., et al. (2008a), Effect of $\mathrm{NO}_{\mathrm{x}}$ on secondary organic aerosol concentrations, Environ. Sci. Technol., 42, 6022-6027.

Lane, T. E., et al. (2008b), Simulating secondary organic aerosol formation using the volatility basis-set approach in a chemical transport model, Atmos. Environ., 42, 7439-7451.

McKeen, S., et al. (2007), Evaluation of several $\mathrm{PM}_{2.5}$ forecast models using data collected during the ICARTT/NEAQS 2004 field study, J. Geophys. Res., 112, D10S20, doi:10.1029/2006JD007608.

Mesinger, F., et al. (2006), North American regional reanalysis, Bull. Am. Meteorol. Soc., 87, 343-360.

Molina, M. J., et al. (2004), Atmospheric evolution of organic aerosol, Geophys. Res. Lett., 31, L22104, doi:10.1029/2004GL020910.

Morgan, W. T., et al. (2010), Airborne measurements of the spatial distribution of aerosol chemical composition across Europe and evolution of the organic fraction, Atmos. Chem. Phys., 10, 4065-4083, doi:10.5194/ acp-10-4065-2010.

Morris, R. E., et al. (2005), Preliminary evaluation of the community multiscale air quality model for 2002 over the southeastern united states, J. Air Waste Manage., 55, 1694-1708.

Morris, R. E., et al. (2006), Model sensitivity evaluation for organic carbon using two multipollutant air quality models that simulate regional haze in the southeastern united states, Atmos. Environ., 40, 4960-4972.

Murphy, B. N., and S. N. Pandis (2009), Simulating the formation of semivolatile primary and secondary organic aerosol in a regional chemical transport model, Environ. Sci. Technol., 43, 4722-4728.

$\mathrm{Ng}$, N. L., et al. (2009), Organic aerosol components observed in worldwide data sets from aerosol mass spectrometry, Atmos. Chem. Phys. Disc., 9, 27,745-27,789.

Perri, M. J., et al. (2009), Secondary organic aerosol production from aqueous photooxidation of glycolaldehyde: Laboratory experiments, Atmos. Environ., 43, 1487-1497.

Polidori, A., et al. (2008), Organic $\mathrm{PM}_{2.5}$ : Fractionation by polarity, ftir spectroscopy, and OM/OC ratio for the pittsburgh aerosol, Aerosol Sci. Technol., 42, 233-246. 
Prisle, N. L., et al. (2010), Humidity influence on gas-particle phase partitioning of $\alpha$-pinene $+\mathrm{O}_{3}$ secondary organic aerosol, Geophys. Res. Lett., 37, L01802, doi:10.1029/2009GL041402.

Pryor, S. C., et al. (2008), A review of measurement and modelling results of particle atmopshere-surface exchange, Tellus, Ser. B, 60, 42-75, doi:10.1111/j.1600-0889.2007.00298.x.

Pun, B. K., et al. (2003), Uncertainties in modeling secondary organic aerosols: Three-dimensional modeling studies in Nashville/Western Tennessee, Environ. Sci. Technol., 37, 3647-3661.

Pye, H. O. T., and J. H. Seinfeld (2010), A global perspective on aerosol from low-volatility organic compounds, Atmos. Chem. Phys., 10, 4079-4141.

Robinson, A. L., et al. (2007), Rethinking organic aerosol: Semivolatile emissions and photochemical aging, Science, 315, 1259-1262.

Sakulyanontvittaya, T., et al. (2008), Monoterpene and sesquiterpene emission estimates for the united states, Environ. Sci. Technol., 42, 1623-1629.

Schwede, D., et al. (2005), Changes to the biogenic emissions inventory system version 3 (BEIS3) 2005, paper presented at 4th Annual CMAS User's Conference, Friday Center, UNC-Chapel Hill, NC, 26-28 Sept. (Available at http://www.cmascenter.org/html/2005_conference/ abstracts/2 7.pdf)

Seinfeld, J. H., and S. N. Pandis (1998), Atmospheric Chemistry and Physics: From Air Pollution to Climate Change, John Wiley, Hoboken, N. J.

Seinfeld, J. H., and S. N. Pandis (2006), Atmospheric Chemistry and Physics: From Air Pollution to Climate Change, John Wiley, Hoboken, NJ.

Shrivastava, M. K., et al. (2008), Effects of gas-particle partitioning and aging of primary emissions on urban and regional organic aerosol concentrations, J. Geophys. Res., 113, D18301, doi:10.1029/2007JD009735.

Spak, S. N., and T. Holloway (2009), Seasonality of speciated aerosol transport over the great lakes region, J. Geophys. Res., 114, D08302, doi:10.1029/2008JD010598.

Stanier, C. O., et al. (2008), Parameterization of secondary organic aerosol mass fractions from smog chamber data, Atmos. Environ., 42, 2276-2299.

Tang, W., et al. (2004), Spatial variations of $\mathrm{PM}_{2.5}$ during the Pittsburgh air quality study, Aerosol Sci. Technol., 38, 80-90, doi:10.1080/ 02786820490442833
Tsigaridis, K., and M. Kanakidou (2003), Global modelling of secondary organic aerosol in the troposphere: A sensitivity analysis, Atmos. Chem. Phys., 3, 1849-1869.

Tsimpidi, A. P., et al. (2010), Evaluation of the volatility basis-set approach for the simulation of organic aerosol formation in the Mexico City metropolitan area, Atmos. Chem. Phys. Disc., 9, 13,693-13,737.

Turpin, B. J., and H.-J. Lim (2001), Species contributions to $\mathrm{PM}_{25}$ mass concentrations: Revisiting common assumptions for estimating organic mass, Aerosol Sci. Technol., 35, 602-610.

U.S. Environmental Protection Agency (USEPA) (2001), 1999 National Emissions Inventory Documentation and Data, Off. of Air Quality Planning and Standards, Washington, D. C. (Available at http://www.epa. gov/ttn/chief/net/1999inventory.html)

U.S. Environmental Protection Agency (USEPA) (2002), Office of Transportation and Air Quality, User's guide to Mobile6.1 and Mobile6.2: Mobile Source Emission Factor Model, Washington, D. C. (Available at http://www.epa.gov/otaq/m6.html)

U.S. Environmental Protection Agency (USEPA) (2003), User's Guide: Air Quality System, Washington, D. C. (Available at www.epa.gov/ttn/ airs/airsaqs/manuals/AQSUserGuide.pdf)

U.S. Environmental Protection Agency (USEPA) (2004), 2002 Nationa Emissions Inventory Documentation, Washington, D. C. (Available at http://www.epa.gov/ttn/chief/net/2002inventory.html)

Wittig, A. E., et al. (2004), Pittsburgh air quality stuy overview, Atmos. Environ., 38, 3107-3125.

Zhang, Q., et al. (2007), Ubiquity and dominance of oxygenated species in organic aerosols in anthropogenically influenced northern hemisphere midlatitudes, Geophys. Res. Lett., 34, L13801, doi:10.1029/2007GL029979.

B. N. Murphy and S. N. Pandis, Department of Chemical Engineering, Carnegie Mellon University, 5000 Forbes Ave., Pittsburgh, PA 15213, USA. (spyros@andrew.cmu.edu) 